\title{
Zinc(II) Chelate Binds to Fibrinogen and Its aC Region
}

\author{
Ralph Butkowski ${ }^{1, *}$, Derek King ${ }^{2}$, Perla Cortes ${ }^{3}$ \\ ${ }^{1}$ Biology Department, Augsburg University, Minneapolis Minnesota, USA \\ ${ }^{2}$ School of Public Health, Environmental Health, University of Minnesota, Minneapolis Minnesota, USA \\ ${ }^{3}$ Molecular Diagnostics Laboratory, University of Minnesota, Minneapolis, Minnesota, USA
}

\section{Email address:}

butkowsk@augsburg.edu (R. Butkowski), King1214@umn.edu (D. King), perlacortes1844@gmail.com (P. Cortes)

${ }^{*}$ Corresponding author

\section{To cite this article:}

Ralph Butkowski, Derek King, Perla Cortes. Zinc(II) Chelate Binds to Fibrinogen and Its $\alpha \mathrm{C}$ Region. Advances in Biochemistry. Vol. 9, No. 1, 2021, pp. 11-17. doi: 10.11648/j.ab.20210901.13

Received: February 26, 2021; Accepted: March 17, 2021; Published: March 26, 2021

\begin{abstract}
Fibrinogen is the immediate precursor of fibrin blood clots. When fibrinogen is cleaved by thrombin, it assembles into fibrin polymers through intermolecular interactions where calcium and zinc ions may both be involved. Fibrinogen's $\alpha \mathrm{C}$ domains play a major role in fibrin polymer assembly, and they contain a $\mathrm{Zn}^{2+}$ binding sites based on peptide studies. However, $\mathrm{Zn}^{2+}$ binding to natural $\alpha \mathrm{C}$ and fibrin (ogen) remains to be demonstrated. The objective of this study was to directly demonstrate $\mathrm{Zn}^{2+}$ interactions with purified fibrinogen and its $\alpha \mathrm{C}$ region. Both human and bovine $\alpha \mathrm{C}$ regions were investigated due to the significant differences in their protein sequences. To detect $\mathrm{Zn}^{2+}$ binding, chelated $\mathrm{Zn}^{2+}$ in the form of $\mathrm{Zn}^{2+}$ nitrilotriacetic acid linked to alkaline phosphatase tracer (ZnTAP) was prepared and used in ELISA and Western blot style methods. Gel electrophoresis was used to monitor changes to fibrinogen after reaction with plasmin. Human and bovine $\alpha \mathrm{C}$ regions were obtained by limited plasmin digests of fibrinogen and purified by Con-A and Zn-immobilized metal ion chromatography. The results showed ZnTAP binding to fibrinogen in solution and inhibition of binding to fibrinogen coated microplates by ELISA. Inhibition concentrations (IC50) of $0.58 \mu \mathrm{M}$ for human fibrinogen and $0.26 \mu \mathrm{M}$ for bovine fibrinogen were determined. Blot probes revealed ZnTAP binding to fibrinogen with disulfide bonds intact and to the $\mathrm{A} \alpha$ and $\mathrm{B} \beta$ chains with disulfide bonds reduced. Reduced $A \alpha$ chain reaction was less than that of intact fibrinogen and the reduced $B \beta$ chain was only weakly reactive. With plasmin treatment, ZnTAP binding decreased by ELISA in parallel with the degradation of $\alpha \mathrm{C}$ region by gel electrophoresis analysis. Purified $\alpha \mathrm{C}$ bound ZnTAP in ELISA and on Western blots. In this study we demonstrated that $\mathrm{Zn}^{2+}$ binds to fibrinogen and its $\mathrm{A} \alpha$ and $\mathrm{B} \beta$ chains, and to the $\alpha \mathrm{C}$ region of the $\mathrm{A} \alpha$ chain. The results support a role for protein conformation in $\mathrm{Zn}^{2+}$ binding and demonstrate the utility of the ZnTAP complex with tracer for fibrinogen binding interactions.
\end{abstract}

Keywords: Fibrinogen, $\alpha$ C Region, Zinc(II) Chelate, Plasmin

\section{Introduction}

Fibrinogen functions in hemostasis as the precursor to fibrin blood clots. It is an elongated molecule with two sets of three protein chains $(\mathrm{A} \alpha, \mathrm{B} \beta \text { and } \gamma)_{2}$ [1]. The six chains are arranged head-to-head near their amino termini forming a central $\mathrm{E}$ region [2]. From $\mathrm{E}$ the two sets of chains extend in opposing directions, leading to two D regions $[3,4]$. The A $\alpha$ chains split away from $\mathrm{D}$ regions as a connector sequence leading to the $\alpha \mathrm{C}$ domains.

Fibrinogen is converted to fibrin monomers as thrombin cleaves peptides from the $\mathrm{A} \alpha$ and $\mathrm{B} \beta$ chains. End-to-end and staggered lateral association of fibrin monomers generate fibrin polymers through interactions among $\mathrm{D}$ and $\mathrm{E}$ domains $[5,6]$. The $\alpha \mathrm{C}$ domains also are released from their intramolecular docking sites with thrombin cleavage of $\mathrm{A} \alpha$ and $\mathrm{B} \beta$ chains, and they form intermolecular associations with other $\alpha \mathrm{C}$ domains during polymer assembly. The transglutaminase, factor XIII, catalyzes covalent cross linking between $\gamma$ chains and among $\alpha \mathrm{C}$ domains to strengthen and stabilize the fibrin clot [5].

Fibrin clots are broken down by plasmin. In-vitro studies on fibrinogen define a characteristic set of early plasmin cleavages whereby the $\alpha \mathrm{C}$ region of the $\mathrm{A} \alpha$ chain is rapidly released and degraded before other observable cleavages (by SDS-PAGE) to B $\beta$ and $\gamma$ chains take place $[2,7]$. Fibrinogen 
des- $\alpha C$, known as fragment $X$, degrades more slowly by plasmin cleavage between the $\mathrm{D}$ and $\mathrm{E}$ regions. Fragments $\mathrm{X}$, $\mathrm{D}$ and $\mathrm{E}$ contain most of the mass of fibrinogen $\mathrm{B} \beta$ and $\gamma$ chains and a small part of the A $\alpha$ chain [8]. These fragments are cleaved further into smaller fragments by plasmin.

In vitro studies demonstrated that $\alpha \mathrm{C}$ participates in intermolecular associations of fibrin promoted by calcium and zinc ions either separately or in combination, and at separate metal binding sites [9, 10]. A source of the $\mathrm{Zn}^{2+}$ is from platelets that aggregate on injured tissue where they release a localized bolus of $\mathrm{Zn}^{2+}$ for fibrin assembly [11]. Indirect evidence for the role $\alpha \mathrm{C}$ in fibrin assembly comes from fragment $\mathrm{X}$ which forms polymers with different physical properties than occur with intact fibrin $[10,12] . \mathrm{Zn}^{2+}$ binding to $\alpha \mathrm{C}$ from purified fibrinogen has yet to be characterized, however a peptide construct containing two histidine residues of human $\alpha \mathrm{C}$ (H563-H564) binds to $\mathrm{Zn}^{2+}$ and links to heparin [13]. It is not known whether or not this site also functions in polymerization of fibrin. Homologs of this site vary in amino acid sequence across species thus complicating the prospects of finding common sites of $\mathrm{Zn}^{2+}$ involvement in fibrin function [13]. For example, bovine $\alpha \mathrm{C}$ has a 21 amino acid gap at the human $\mathrm{Zn}^{2+}$ binding site, as presented in Figure 1. However, bovine $\alpha \mathrm{C}$ has another location His495-His496 which could serve a similar binding function (Figure 1). Other differences between human and bovine $\alpha \mathrm{C}$ are additional sequence gaps in bovine $\alpha \mathrm{C}$ and its considerably smaller size [14].

Immobilized metal ion chromatography (IMAC) methods use chelated metal ions to bind His residues on proteins and is used for protein purification [15]. This method has been demonstrated for fibrinogen as well as fragment $\mathrm{D}[9,16] . \alpha \mathrm{C}$ ought to bind IMAC resins if there are exposed binding site(s) of sufficient affinity. ZnTAP is similar to Zn-IMAC resin with respect to the NTA-chelated $\mathrm{Zn}^{2+}$ format, while differing in having alkaline phosphatase instead of the chromatography resin. On the assumption that $\mathrm{ZnTAP}$ would bind to $\mathrm{Zn}^{2+}$ sites, the present study tested fibrinogen and $\alpha \mathrm{C}$ by ELISA methods and by Western blot probes. $\alpha \mathrm{C}$ was then purified by $\mathrm{Zn}$-IMAC and used to directly demonstrate zinc ion binding to this region of fibrinogen.

The goals of this study were to 1) demonstrate $\mathrm{Zn}^{2+}$ binding with ZnTAP to fibrinogen, and to the $\alpha \mathrm{C}$ region prepared from natural fibrinogen, and 2) compare the binding of ZnTAP by human and bovine $\alpha \mathrm{C}$ in view of their differences in $\alpha \mathrm{C}$.

A

Human 540 GEEVSETESRGSESGIFTNTKESSSHHPGIAEFP 570

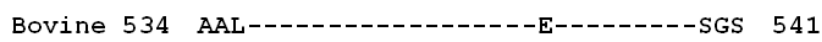

B

Human 486 EDGSDCPEAMDLGTL-SGIGTLDGERHRHPDEAA 517

Bovine 480 EDGSDCGDA-DFDWHHTFPSRGNLDD--FFHRDK 508

Figure 1. Comparison of sequences within human and bovine $\alpha C$ regions. His-His residues, underlined, are in different locations in the two species.

\section{Materials and Methods}

\subsection{Reagent Sources}

Millipore corporation was the source of human fibrinogen and some of the bovine fibrinogen. Bovine plasma was from PelFreez Biologicals. Plasmin was from Haematologic Technologies, Inc. Ni-His-60 resin was from Clontech Laboratories. Precast stain-free gels and other electrophoresis reagents were from Bio-Rad. Con-A Sepharose was from Sigmaaldrich. Nickel-NTA-alkaline phosphatase and Western blot substrate were obtained from KPL. Bovine fibrinogen was prepared by salt precipitation and IMAC as described [16]. Antibody sc-398806 (C-7) to human $\alpha \mathrm{C}$ was from Santa Cruz Biotechnology.

\subsection{Preparation of $\mathrm{ZnTAP}$}

ZnTAP was derived from Ni-NTA-alkaline phosphatase. One-tenth $\mathrm{ml}$ of Ni-NTA-alkaline phosphatase was diluted to $2 \mathrm{ml}$ with TBS, $0.1 \mathrm{mg} / \mathrm{ml}$ bovine serum albumin, $\mathrm{pH} 7.4$. Then $0.1 \mathrm{ml}$ of $0.1 \mathrm{M}$ EDTA was added and the mixture was dialyzed into 3 changes of TBS. The sample was next dialyzed into 2 changes of the same buffer containing $10 \mathrm{mM}$ zinc sulfate, $5 \mathrm{mM}$ magnesium chloride at $\mathrm{pH} 6.0$ in order to load NTA with zinc and alkaline phosphatase with magnesium. The product was finally dialyzed into several changes of TBS, $\mathrm{pH}$ 7.4. Control samples without zinc were prepared in parallel.

Complexometric titration of ZnTAP was done with EDTA to demonstrate specificity of the reagent and to measure zinc content. ZnTAP at a concentration giving greater than $75 \%$ of maximum response to fibrinogen by ELISA was incubated with varying concentrations of EDTA. The mixtures were applied to fibrinogen coated microplates and then processed and tested for alkaline phosphatase hydrolysis of $\rho$ NPP. The concentration of EDTA that completely inhibited ZnTAP was recorded.

Zn-IMAC resin was prepared from Ni-IMAC resin by metal ion exchange according to the Clontech User Manual.

\subsection{Plasmin Digestion of Fibrinogen}

Fibrinogen was dialyzed into TBS, $\mathrm{pH} 7.4$ and plasmin was added to give a mass ratio of plasmin to fibrinogen of 1:1000 for electrophoresis and ELISA inhibition studies. A 1:15,000 dilution of $0.42 \mathrm{mg} / \mathrm{ml}$ of plasmin was used for experiments where fibrinogen was first coated onto microplates and the reacted with plasmin. Plasmin reactions were terminated by addition of PMSF to $1 \mathrm{mM}$, followed by addition of 6-aminohexanoic acid (EACA) in TBS to $0.1 \mathrm{M}$. For SDS-PAGE, these samples were mixed with 2 volumes of SDS-sample buffer and heated to $60^{\circ} \mathrm{C}$ for 10 minutes. Some reaction samples were heated to $75^{\circ}$ for 10 minutes to precipitate residual fibrinogen and fragment $X$ [17]. The precipitate and soluble $\alpha \mathrm{C}$ fractions were analyzed by SDS-PAGE. The soluble fraction was also used for the purification of $\alpha \mathrm{C}$. 


\subsection{ELISA}

For direct ELISA, microplates were coated with $5 \mathrm{mg} / \mathrm{ml}$ fibrinogen or $\alpha \mathrm{C}$ in PBS, blocked with $0.1 \mathrm{mg} / \mathrm{ml}$ of bovine serum albumin, and then incubation with ZnTAP. Wells were then washed with TBST, incubated with $1 \mathrm{mg} / \mathrm{ml} \rho \mathrm{NPP}$ in 0.1 $\mathrm{M}$ Tris- $\mathrm{HCl}, 5 \mathrm{mM} \mathrm{MgCl} 2, \mathrm{pH} 9.3$, and monitored at $415 \mathrm{~nm}$. A concentration of ZnTAP of greater than $75 \%$ of maximum response in the direct assay was used for inhibition assays. Direct ELISAs using plasmin reacted fibrinogen at E:S of 1:000 was performed and terminated with PMSF and $\varepsilon A C A$ over a time course. In other experiments, microplates were first coated with fibrinogen, then blocked and incubated with plasmin over a time sequence. At the desired incubation times, reactions were stopped with PMSF and $\varepsilon A C A$ and then processed as described above.

For inhibition ELISA using fibrinogen, a constant pre-determined concentration of ZnTAP was incubated for 60 minutes with varying concentrations of fibrinogen and the mixtures were transferred to microplates that had been coated with $5 \mu \mathrm{g} / \mathrm{ml}$ of fibrinogen, blocked with serum albumin, and processed as above to estimate IC50 [18]. After 60 minutes incubation time the wells were emptied, washed and $\rho \mathrm{NPP}$ was added. Absorbance of the NPP product was monitored at $415 \mathrm{~nm}$. Plasmin-digested fibrinogen was similarly tested for inhibition of ZnTAP on fibrinogen coated microplates.

\section{5. $\alpha$ C Preparation}

$\alpha \mathrm{C}$ from human and bovine fibrinogen was purified by Con-A chromatography [19] and Zn-IMAC. Typically, $20 \mathrm{mg}$ of fibrinogen in $6 \mathrm{ml} \mathrm{TBS}$, pH 7.4 was digested for 10 minutes with 2 ug of plasmin. Digests were terminated with PMSF and EACA and heated to $75^{\circ}$ for 10 minutes [17]. The heat-treated products were spun for 5 minutes at $12,000 \mathrm{x} \mathrm{g}$, and the supernatant containing $\alpha \mathrm{C}$ was re-spun. The soluble fraction was applied to $2 \mathrm{ml}$ columns of Con-A in TBS and unbound protein containing $\alpha \mathrm{C}$ was further purified on $\mathrm{Zn}$-IMAC columns. $\mathrm{NaCl}(1 \mathrm{M})$ in TBS, pH 7.4 was added to bring the concentration of $\mathrm{NaCl}$ to $0.3 \mathrm{M}$ and the samples were applied to $2 \mathrm{ml}$ columns of $\mathrm{Zn}$-IMAC. Bound $\alpha \mathrm{C}$ was released in the same buffer with added $0.005 \mathrm{M}$ and then $0.1 \mathrm{M}$ imidazole.

\section{Results}

\subsection{Characterization of the ZnTAP Reaction with Fibrinogen}

ZnTAP was prepared for the purpose of directly demonstrating $\mathrm{Zn}^{2+}$ binding to fibrinogen and to the $\alpha \mathrm{C}$ region of fibrinogen. To prepare ZnTAP, EDTA was added to Ni-NTA-alkaline phosphatase to remove $\mathrm{Ni}^{2+}$. Then $\mathrm{Zn}^{2+}$ was added back to NTA through dialysis changes. ZnTAP bound to fibrinogen by ELISA while control reagent lacking $\mathrm{Zn}^{2+}$ did not bind. Alkaline phosphatase in the control hydrolyzed $\rho N P P$, indicating that $\mathrm{Zn}^{2+}$ had been exchanged for zinc ions in the functioning reagent. Complexometric titration of ZnTAP with EDTA demonstrated complete displacement of $\mathrm{Zn}^{2+}$.
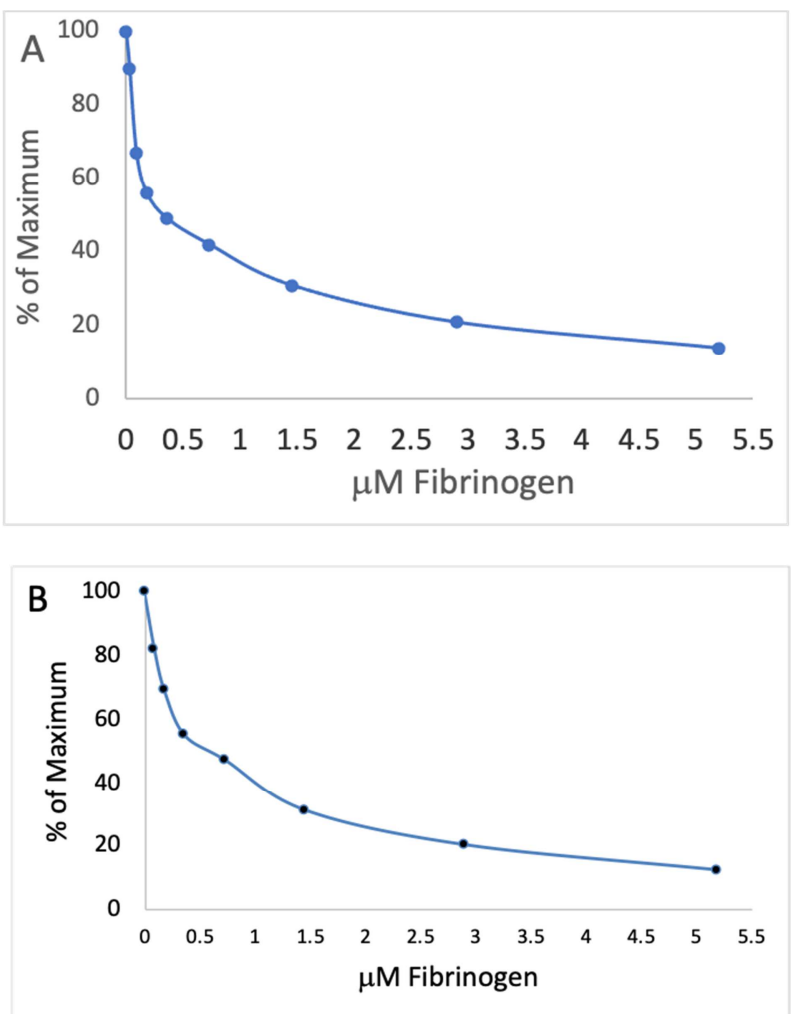

Figure 2. Inhibition by A) human and B) bovine fibrinogen of ZnTAP binding to solid phase fibrinogen by ELISA. Assays were done in duplicate.

Inhibition ELISA was performed by mixing varying concentrations of fibrinogen with a pre-determined (by direct ELISA) constant concentration of ZnTAP and then applying the mixtures to fibrinogen-coated microplates. Results from the inhibition measurements yield IC50 values, by interpolation, of $0.58 \mu \mathrm{M}$ and $0.26 \mu \mathrm{M}$ for human and bovine fibrinogen respectively. The inhibition curves reveal similar profiles for human (Figure $2 \mathrm{~A}$ ) and bovine (Figure $2 \mathrm{~B}$ ) fibrinogen. Maximum 415 values of 1.6 in A and 1.5 in B were obtained. The values are an average of duplicate determinations.

Characterization of fibrinogen and $\alpha \mathrm{C}$ by SDS-PAGE and Western blot probes is shown in Figure 3. The high molecular weight bands of bovine and human fibrinogen are seen in Figure 3A, lanes 1 and 2. Upon reduction of disulfide bonds, bovine $\mathrm{A} \alpha, \mathrm{B} \beta$ and $\gamma$ chain molecular weights were $60 \mathrm{kD}, 52$ $\mathrm{kD}$ and $47 \mathrm{kD}$, lane 3 . Human $\mathrm{A} \alpha, \mathrm{B} \beta$ and $\gamma$ chain sizes were $66 \mathrm{kD}, 53 \mathrm{kD}$ and $48 \mathrm{kD}$, lane 4. Figure 3, Panels B-D represents ZnTAP probes of Western blots of human fibrinogen with disulfide bonds intact (Panel B) and with disulfide bonds reduced (Panel C). Panel D represents $\alpha \mathrm{C}$ from the heat-soluble fraction of plasmin digested human fibrinogen. The darker background in $\mathrm{C}$ resulted from longer exposure to the substrate compared to B and D. Blots of intact fibrinogen develop quickly, while reduced chains are less reactive based on slower blot development times. For intact fibrinogen the reaction took about 1 minute, and about 5 minutes was typically required in order to visualize reduced $\mathrm{A} \alpha$ chain. A signal from the $\mathrm{B} \beta$ chain was consistently detected at 10-minute incubation time. Comparable results 
were observed with fibrinogen of human and bovine origin. Fibrinogen $\gamma$ chains were generally not observed to produce a signal except occasionally trace reactions were detected with prolonged incubation. Trace reactions at the $\gamma$ position of the blot were attributed to partial degradation of the $\mathrm{B} \beta$ chain that migrated close to the $\gamma$ chain. The $\gamma$ chain was therefore considered to be negative.

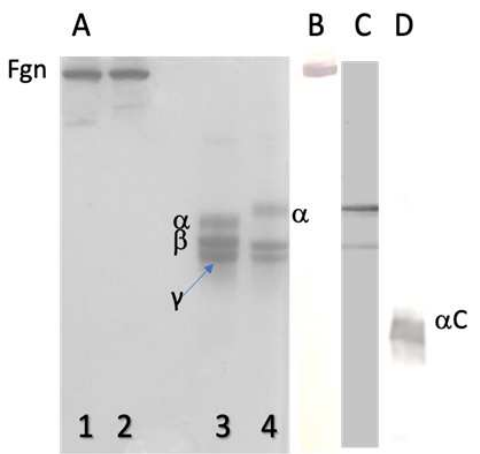

Figure 3. A) SDS-PAGE of intact bovine and human fibrinogen, 1-2, and reduced 3,4. B-C) Intact and reduced human fibrinogen blots probed with ZnTAP, and Panel D, probe of $\alpha C$. Panels are from separate gels.

\subsection{Reaction of ZnTAP with Fibrinogen Fragments}

Plasmin reactions with fibrinogen generated the characteristic early fragments, $\alpha \mathrm{C}$ and fibrinogen-des $\alpha \mathrm{C}$ (fragment X). Plasmin digests of fibrinogen at $2 \mathrm{mg} / \mathrm{ml}$ were obtained by incubation with $2 \mu \mathrm{g} / \mathrm{ml}$ of plasmin and samples taken at various reaction times were terminated with plasmin inhibitors. Reactions were heated at $75^{\circ}$ for 10 minutes to precipitate residual fibrinogen and fragment $\mathrm{X}$, leaving $\alpha \mathrm{C}$ in solution. The heat-insoluble samples taken over 32 minutes of plasmin treatment were analyzed by SDS-PAGE as shown in Figure $4 \mathrm{~A}$ insert. SDS-PAGE of fibrinogen with disulfide bonds reduced is the best way demonstrate changes in the separate chains.

Scans of the Coomassie Blue stained gel at time 0 (Panel A), and at 16 minutes in Panel $B$ illustrate rapid degradation of the $A \alpha$ chain while changes to $B \beta$ occur more slowly and $\gamma$ chain appears slightly elevated by 16 minutes. The results by SDS-PAGE are consistent with the known pattern for fibrinogen reaction with low levels of plasmin where the $\mathrm{A} \alpha$ chain is degraded before $B \beta$ and $\gamma$ chains degradation is detected $[7,8]$.

The $\alpha \mathrm{C}$ bands of the heat-soluble plasmin digests are closely spaced bands from 37-39 kDa for human, and 31-34 $\mathrm{kDa}$ for bovine $\alpha \mathrm{C}$. Figure 5 compares changes to bovine $\mathrm{A} \alpha$ chain (solid line) and $\alpha \mathrm{C}$ (dashed line) with time of plasmin exposure measured by gel densitometry. The half-life of the $\mathrm{A} \alpha$ chain was 4 to 5 minutes, and by 30 minutes only traces remain. The maximum concentration of $\alpha \mathrm{C}$ occurs within 8 minutes of reaction with plasmin for both human and bovine fibrinogen. The half-life of $\alpha \mathrm{C}$ was about 24 minutes indicating that it is more stable to plasmin than the $\mathrm{A} \alpha$ chain. $\alpha \mathrm{C}$ degradation products are present for a short time after $\alpha \mathrm{C}$ is gone. Fragments of 21 and $18 \mathrm{kDa}$ for human, and 18 and 15 $\mathrm{kDa}$ from bovine $\alpha \mathrm{C}$ appear, and then degrade further with time (not shown).

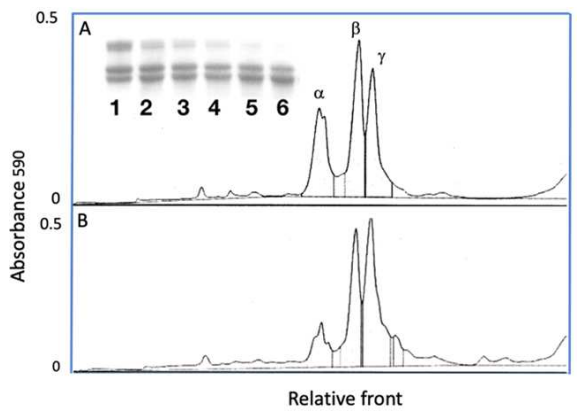

Figure 4. Densitometer scans and gels (insert) of human fibrinogen degradation with plasmin. A) scan of gel lane 1 at 0 min and B) lane 5 at 16-min. reaction.

Plasmin digests of bovine fibrinogen were first analyzed by direct ELISA. Over a 64-minute reaction time, the reactivity with ZnTAP decreased rapidly (Figure 6). The decrease in the ELISA values is similar to the decrease over time of $\alpha \mathrm{C}$ by SDS-PAGE suggesting that $\alpha \mathrm{C}$ continues to bind ZnTAP after it is cleaved from $A \alpha$ chain. To confirm the results by other approaches, fibrinogen was first bound to microplates and then digested with plasmin over a time course and analyzed by ELISA. The results were qualitatively the same when fibrinogen was digested with plasmin before being coated to the microplate as when fibrinogen was first applied to the microplate and then digested with plasmin (not shown).

An inhibition experiment was next performed on a plasmin digest whereby samples were inactivated over 60 minutes and then mixed with ZnTAP and applied to fibrinogen coated microplates (Figure 7). Control sample, C, represents ZnTAP in BSA without fibrinogen. The other samples contained ZnTAP mixed with $250 \mathrm{ug} / \mathrm{ml}$ of bovine fibrinogen digests. At one minute, activity was inhibited by $82 \%$, having $18 \%$ signal compared to the control, and after 60 minutes. reaction, just $12 \%$ inhibition capacity remained (the signal is $88 \%$ of control). Numbers above the bars in Figure 7 indicate percent of control value for each sample. The A415 of the control was 1.4. ELISA results collectively suggest that the decrease in ZnTAP binding to plasmin-reacted fibrinogen resulted from plasmin degradation of the ZnTAP binding entity.

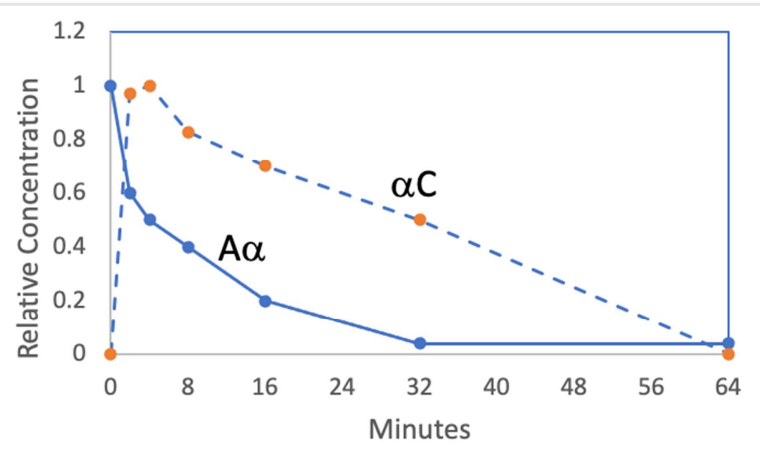

Figure 5. Relative concentration of bovine fibrinogen Aa chain and $\alpha C$ with plasmin digestion time measured by gel densitometry. 


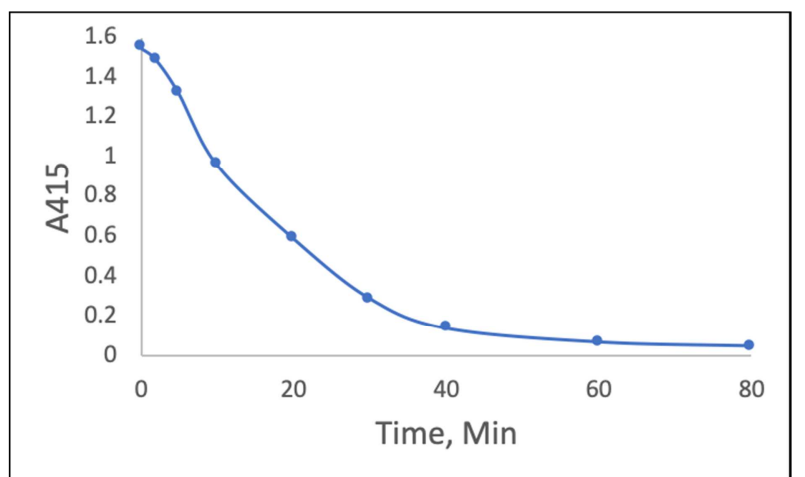

Figure 6. Binding of ZnTAP to bovine fibrinogen versus plasmin reaction time by direct ELISA.

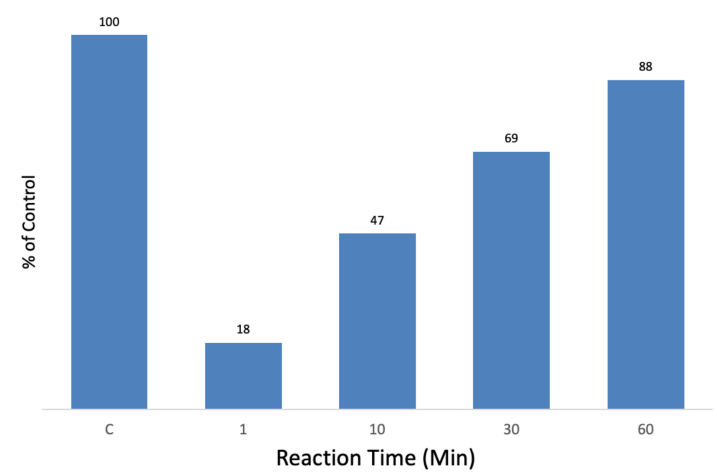

Figure 7. Inhibition of ZnTAP by plasmin-digested bovine fibrinogen. Values above bars are \% of control A415 and reflect the loss of capacity for inhibition.

\subsection{Purification and Confirmation of $\alpha C$}

$\alpha \mathrm{C}$ was isolated in order to confirm ZnTAP binding to the purified protein. Fibrinogen was digested with plasmin for 10 minutes and the reaction was terminated with PMSF and $\varepsilon A C A$. The sample was heated to precipitate non- $\alpha \mathrm{C}$ fragments and the soluble fraction was passed through a Con-A column to remove residual carbohydrate-containing material. $\alpha \mathrm{C}$ was present in the Con-A unbound fraction, and this fraction was applied to $\mathrm{Zn}$-IMAC columns as presented in Figure 8. Most low molecular weight peptides failed to bind to the column, while $\alpha \mathrm{C}$ bound and then was released when imidazole was added to the column buffer. SDS-PAGE of the peak samples shown in Figure 8 inset reveal that $\alpha \mathrm{C}$ is present in column fractions 2-4. Both human and bovine $\alpha \mathrm{C}$ were successfully prepared by Zn-IMAC using identical conditions. ZnTAP reacted with both purified human and bovine $\alpha \mathrm{C}$ by ELISA and blotting methods (not shown).

Monoclonal antibody, C-7, to human $\alpha \mathrm{C}$ was used to confirm the identity of $\mathrm{Zn}$-IMAC purified $\alpha \mathrm{C}$.

ELISA values for purified human $\alpha \mathrm{C}$ were $13 \mathrm{x}$ to $19 \mathrm{x}$ background and were $80 \%$ of the values obtained with a human fibrinogen control. ELISA values for bovine $\alpha \mathrm{C}$ were 2.5-times background with C-7 antibody. Western blots probed with $\mathrm{C}-7$ showed reactivity with human $\alpha \mathrm{C}$ and trace reaction with bovine $\alpha \mathrm{C}$.

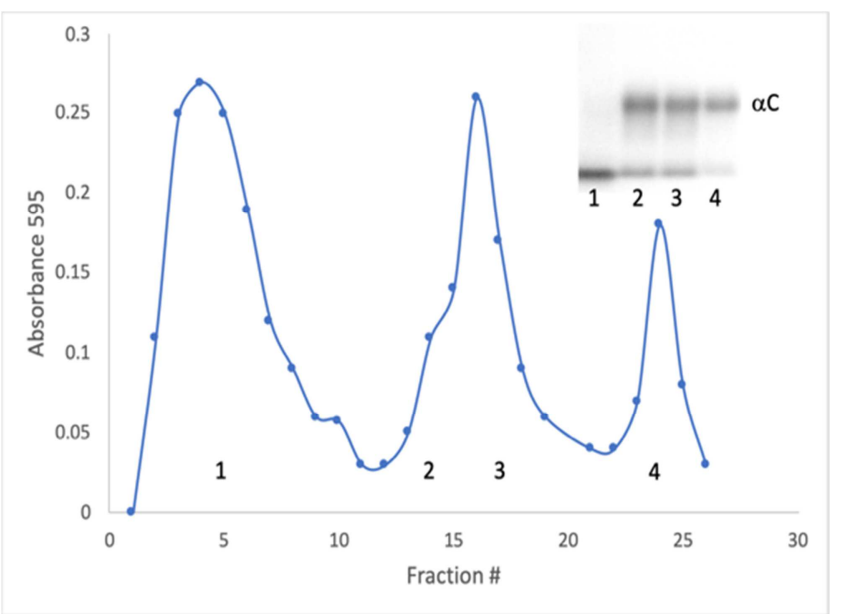

Figure 8. Preparation of bovine $\alpha C$ by Zn-IMAC. Insert: Chromatogram fractions 1-4 by SDS-PAGE.

\section{Discussion}

It was of interest in this study to confirm $\mathrm{Zn}^{2+}$ binding to $\alpha \mathrm{C}$ prepared from isolated fibrinogen, and to enhance the understanding of the roles of $\mathrm{Zn}^{2+}$ in coagulation [11]. For this purpose, a zinc chelate tag (ZnTAP) was prepared and used to demonstrate $\mathrm{Zn}^{2+}$ binding to fibrinogen and its $\alpha \mathrm{C}$ region.

By probing Western blots and by ELISA methods, ZnTAP was shown to bind fibrinogen and $\alpha \mathrm{C}$. In addition, $\mathrm{Zn}$-IMAC resin bound $\alpha \mathrm{C}$ and was used as the final step in its purification. $\alpha \mathrm{C}$ was released from $\mathrm{Zn}$-IMAC resin with imidazole, indicating that histidine is likely to be involved in interactions between $\alpha \mathrm{C}$ and $\mathrm{Zn}^{2+}$. ZnTAP binding by ELISA decreased in parallel with the release and further degradation of the $\alpha \mathrm{C}$ region from fibrinogen by plasmin. The collective observations indicate the $\alpha \mathrm{C}$ region binds $\mathrm{Zn}^{2+}$. The location of the binding site(s) within the protein sequence is not identified in this study but the separate His-His sequences in the human and bovine proteins seem likely to be involved.

Other studies by indirect methods previously concluded that $\alpha \mathrm{C}$ interacts with $\mathrm{Zn}^{2+}$ [12]. Additionally, synthetic peptides corresponding to a sequence from human $\alpha \mathrm{C}$ demonstrated that His545-His546 is a site where $\mathrm{Zn}^{2+}$ links heparin to $\alpha \mathrm{C}$ [13]. If ZnTAP binds to the human His545-His546 site, it seems reasonable that it also binds to the His493-His494 site in bovine $\alpha \mathrm{C}$. Besides linking heparin, $\mathrm{Zn}^{2+}$ promotes fibrin polymer formation [5, 10]. However further studies are needed to reveal the interactions that take place between $\mathrm{Zn}^{2+}$ and fibrin as blood clots.

From investigations using recombinant $\alpha \mathrm{C}$ protein, its interactions with the $\mathrm{E}$ region at the $\mathrm{N}$-terminal of the $\mathrm{B} \beta$ chain are defined [5] This interaction is disrupted upon cleavage of fibrinopeptide $\mathrm{B}$, and then $\alpha \mathrm{C}$ associates intermolecularly with $\alpha \mathrm{C}$ regions of adjacent fibrin molecules. The switch allows for aggregation of fibrin protofibrils and fibrin assembly. While these interactions can occur in the absence of metal ions it is of interest to examine the roles of zinc and calcium ions in the process since fibrin polymer formation is accelerated by the ions [20]. In addition, possible 
roles for metal ions in $\alpha \mathrm{C}$ functions such as cell adhesion, wound healing and fibrinolysis [21] are of interest. Moreover, mutations in $\alpha \mathrm{C}$ that result in clotting disorders and amyloid deposition in some cases, could be investigated further [22]. Elucidation of the role of metal ions in fibrin formation will permit a better understanding of the mechanisms involved in abnormal states.

Although bovine and human $\alpha \mathrm{C}$ differ substantially in their amino acid sequences and size, their reactions with ZnTAP were essentially identical in this study. However, the picture becomes less intuitive when considering sequence homology among species For example, while most primate species are homologous to human $\mathrm{A} \alpha$ chain at the site represented by His545-His546, chimpanzee and orangutan each lack one of these His residues [13] Adjacent His residues aren't a requirement for $\mathrm{Zn}^{2+}$ binding, as closely spaced His residues can function in this capacity [14]. Therefore, closely spaced His in the $\alpha \mathrm{C}$ regions of the latter two species could involve $\mathrm{Zn}^{2+}$ binding.

In contrast to primates, just 3 of 15 mammals contain His-His sites within their $\alpha \mathrm{C}$ regions [13]. Highly conserved His residues that exist in $\alpha \mathrm{C}$ and are shared by both primates and other mammals are potential $\mathrm{Zn}^{2+}$ interaction sites. Further laboratory and predictive modeling studies are necessary to discover the modes and sites of $\mathrm{Zn}^{2+}$ binding to $\alpha \mathrm{C}$ and their functions [23]. The B $\beta$ chain reacted with ZnTAP and it lacks a His-His sequence while $\gamma$ chain has a His-His site but is unreactive by Western blot analysis. These observations suggest that the conformation of binding sites is significant in metal ion binding.

Although ZnTAP is bulky compared to $\mathrm{Zn}^{2+}$, the reagent worked well judging by its affinity for fibrinogen, and this is consistent with the fact that $\alpha \mathrm{C}$ could be purified by Zn-IMAC. The IC50 values for ZnTAP were similar for human $(0.58 \mu \mathrm{M})$ and bovine $(0.26 \mu \mathrm{M})$ fibrinogen and should be close to the $\mathrm{Kd}$ for this interaction. Values of $\mathrm{Kd}=0.67 \mu \mathrm{M}$ and $1.0 \mu \mathrm{M}$ were reported using FluoZin-1 with human fibrinogen [10]. In studies where $\mathrm{ZnSO}_{4}$ or $\mathrm{ZnCl}_{2}$, were used, different values of $\mathrm{Kd}=18 \mu \mathrm{M}$ [5] and $\mathrm{Kd}=9.4 \mu \mathrm{M}$ were reported [9]. Zinc salts produce zinc oxide and hydroxides that may generate complicating side reactions which could contribute to the differences in $\mathrm{Kd}$ measured by the different methods [24, 25].

\section{Conclusions}

1. $\mathrm{Zn}^{2+}$ binding to intact fibrinogen, reduced $\mathrm{A} \alpha$ and $\mathrm{B} \beta$ chains of fibrinogen, and $\alpha \mathrm{C}$ region of the $\mathrm{A} \alpha$ chain was directly demonstrated with the chelate, ZnTAP.

2. The $\alpha \mathrm{C}$ region of fibrinogen accounts for most of the ZnTAP reaction with fibrinogen.

3. ZnTAP binding to human and bovine fibrinogen and $\alpha \mathrm{C}$ was comparable in spite of their amino acid sequence differences.

\section{Abbreviations}

ZnTAP, Zn-NTA-Alkaline Phosphatase

NTA, nitrilotriacetic acid

IMAC, immobilized metal ion chromatography
TBS, $0.02 \mathrm{M}$ Tris, $0.15 \mathrm{M} \mathrm{NaCl}$, pH 7.4

TBST, TBS containing $0.05 \%$ tween

$\rho N P P$, para-nitro phenylphosphate

NPP, nitro phenylphosphate

PBS, 0.02 M sodium phosphate, 0.145 M NaCl, pH 7.2.

Con-A, concanavalin A

PMSF, phenylmethylsulfonyl fluoride

\section{Acknowledgements}

The authors thank URGO at Augsburg University and the biology department for use of the lab, supplies and equipment.

There are no conflicts of interest.

\section{References}

[1] Medved, L., \& Weisel, J. W. (2009). Recommendations for nomenclature on fibrinogen and fibrin. Journal of Thrombosis $\begin{array}{llll}\text { and Haemostasis, } & 7 & \text { (2), } & 355-359 .\end{array}$ https://doi.org/10.1111/j.1538-7836.2008.03242.x

[2] Everse, S. J. (2002). New insights into fibrin (ogen) structure and function. VoxSanguinis, 83 Suppl 1, 375-382. https://doi.org/10.1111/j.1423-0410.2002.tb05338.x.

[3] Doolittle, R. F., \& Kollman, J. M. (2006). Natively unfolded regions of the vertebrate fibrinogen molecule. Proteins: Structure, Function and Genetics, 63 (2), 391-397. https://doi.org/10.1002/prot.20758.

[4] Pieters M, Wolberg AS. Fibrinogen and fibrin: An illustrated review. Res Pract Thromb Haemost. 2019; 3: 161-172. https://doi.org/10.1002/rth2.12191.

[5] Tsurupa, G., Pechik, I., Litvinov, R. I., Roy R. Hantgan, R. R., Tjandra, N., Weisel, J. W. and Leonid Medved. (2012). On the mechanism of aC polymer formation in fibrin, Biochemistry. 51 (12): 2526-2538. doi: 10.1021/bi2017848.

[6] Mosesson MW. Fibrinogen and fibrin structure and functions. J Thromb Haemost 2005; 3: 1894-904.

[7] Shen, L. L., McDonagh, R. P., McDonagh, J., \& Hermans, J. Early events in the plasmin digestion of fibrinogen and fibrin. Effects of plasmin on fibrin polymerization. J. Biol. Chem. 1977; 252: 6184-6189.

[8] Pizzo, S. V., Taylor, L. M., Schwartz M. L., Hill, R. L., McKee, P. A. Subunit structure of fragment D from fibrinogen and cross-linked fibrin. J. Biol. Chem. 1973; 248:4584-4590.

[9] Marx, G., Hopmeier, P., \& Gurfel, D. (1987). Zinc alters fibrin ultrastructure. Thrombosis and Haemostasis, 57 (1), 73-76. https://doi.org/10.1055/s-0038-1651065.

[10] Henderson, S. J., Xia, J., Wu, H., Stafford, A. R., Leslie, B. A., Fredenburgh, J. C., Weitz, D. A., \& Weitz, J. I. (2016). Zinc promotes clot stability by accelerating clot formation and modifying fibrin structure. Thrombosis and Haemostasis, 115 (3), 533542. https://doi.org/10.1160/TH15-06-0462.

[11] Vu, T. T., Fredenburgh, J. C., \& Weitz, J. I. (2013). Zinc: An important cofactor in haemostasis and thrombosis. Thrombosis and Haemostasis, 109 (3), 421-430. https://doi.org/10.1160/TH12-07-0465. 
[12] Collet, J. P., Moen, J. L. Yuri I. Veklich, Y. I. Oleg V. Gorkun, O. V. Susan T. Lord, S. T., Gilles Montalescot, G., \& Weisel, J. $\mathrm{W}$. The alpha $\mathrm{C}$ domains of fibrinogen affect the structure of the fibrin clot, its physical properties, and its susceptibility to fibrinolysis (2005). Blood, 106: 12, 3824-3830.

[13] Fredenburgh, J. C., Leslie, B. A., Stafford, A. R., Lim, T., Chan, H. H., \& Weitz, J. I. (2013). Zn2+ mediates high affinity binding of heparin to the $\alpha \mathrm{C}$ domain of fibrinogen. Journal of Biological Chemistry, 288(41), 29394-29402. https://doi.org/10.1074/jbc.M113.469916.

[14] Bateman, A., Martin, M. J., O’Donovan, C., Magrane, M., Alpi, E., Antunes, R., Bely, B., Bingley, M., Bonilla, C., Britto, R., Bursteinas, B., Bye-AJee, H., Cowley, A., Da Silva, A., De Giorgi, M., Dogan, T., Fazzini, F., Castro, L. G., Figueira, L., ... Zhang, J. (2017). UniProt: The universal protein knowledgebase. Nucleic Acids Research, 45 (D1), D158-D169. https://doi.org/10.1093/nar/gkw1099.

[15] Block, H., Maertens, B., Spriestersbach, A., Brinker, N., Kubicek, J., Roland Fabis, R., Jo r̈g Labahn, J., \& Scha fer. F. Immobilized-Metal Affinity Chromatography (IMAC): A Review. (2009). In Methods in Enzymology, Chapter 27, 463, 439-473.

[16] Colwell, M., Ahmed, N., \& Butkowski, R. (2017). Detection of histidine-rich glycoprotein and fibrinogen with nickel-enzyme conjugates: Purification of rabbit HRG. Analytical Biochemistry, 525, 67-72. https://doi.org/10.1016/j.ab.2017.02.013

[17] Plow, E. F. (1977). Stability of the Disulfide Bonds of Fibrinogen and Identification of Specific Subsets of Surface-Oriented Histidine Residues Highly Susceptible to Alkylation. European Journal of Biochemistry, 80(1), 55-64. https://doi.org/10.1111/j.1432-1033.1977.tb11855.x

[18] Friguet, B., Chaffotte, A. F., Djavadi-Ohaniance, L., \&
Goldberg, M. E. (1985). Measurements of the true affinity constant in solution of antigen-antibody complexes by enzyme-linked immunosorbent assay. Journal of Immunological Methods, $77 \quad$ (2), 305-319. https://doi.org/10.1016/0022-1759(85)90044-4.

[19] Sobel, J. H., Wu, H. Q. and RE Canfield, R. E. T (1994) The development of assays for the detection of fibrin(ogen)olysis based on $\mathrm{COOH}$-terminal A alpha chain epitopes. Blood 84: 535-546.

[20] Mammadova-Bach, E., \& Braun, A. (2019) Zinc homeostasis in platelet-related diseases. Int. J. Mol. Sci 20(21). https://doi.org/10.3390/ijms20215258.

[21] Litvinov, R. I., Yakovlev, S., Tsurupa, G., Gorcun, O. V., Medved, L., \& Weisel J. (2007) Direct evidence for specific interactions of fibrinogen $\alpha \mathrm{C}$ domains with the $\mathrm{E}$ region and with each other. Biochemistry 46(31):9133-9142. doi:10.1021/bi700944j.

[22] Soria, J., Mirshahi, S., Mirshahi, S. Q., Varin, R., Pritchard, L. L., Soria, C. \& Mirshahi M. (2019) Fibrinogen aC: Its importance in pathophysiology. Research and practice in thrombosis and haemostasis. Wiley periodicals. http://doi.org/10.1002/rth2.12183.

[23] Passerini, A., Andreini, C. Menchetti, S. Rosato, A., \& Frasconi, P. (2007). Predicting zinc binding at the proteome level. BCM Bioinformatics. 8: 39 doi: 10.1186/1471-2105-8-39.

[24] Krezel, A. and Maret, W. (2016). The biological inorganic chemistry of zinc ions. Archives of Biochemistry and Biophysics, 611, 3-19.

[25] Masuoka, J., Hegenauer, J., Van Dyke, B. R. \& Saltman, P. (1993). Intrinsic stoichiometric equilibrium constants for the binding of Zinc(II) and $\mathrm{Cu}(\mathrm{II})$ to the High Affinity Site of Serum Albumin. J. Biol. Chem. 268: 29, 21533-21537. 